\title{
La «poesía matemática» de Edgardo Antonio Vigo: el poema como «intención» y «posibilidad» estética ${ }^{1}$
}

\author{
Juan Rogelio Rosado Marrero \\ Benemérita Universidad Autónoma de Puebla
}

Resumen: Ya desde sus primeras publicaciones en la revista Diagonal Cero (19621969), Edgardo Antonio Vigo (1928-1997) va construyendo una obra poética que se contrapone a la visión hegemónica impuesta por las instituciones literarias. Un claro ejemplo de ello son los denominados «poemas matemáticos»; un grupo de composiciones visuales que emplean diversas formas, palabras, números y colores. Por consiguiente, este artículo analiza la manera en la cual Vigo cuestiona, por medio de sus propuestas estéticas radicales, tanto el concepto mismo de poema como los procesos de lectura e interpretación literaria. Esto con el objetivo de constituir una nueva forma de ver y entender el quehacer poético.

Palabras clave: Edgardo Antonio Vigo, «poema matemático», «Nueva Poesía Platense», Poème Mathématique Baroque, poesía neovanguardista.

Edgardo Antonio Vigo's «mathematical poetry»: the poem as «intention» and «possibility» aesthetic

Abstract: Since his first publications in the magazine Diagonal Cero (1962-1969), Edgardo Antonio Vigo (1928-1997) has been building a poetic work that contrasts with the hegemonic vision imposed by literary institutions. A clear example of this is the «mathematical poems»; a group of visual compositions that employ various forms, words, numbers and colors. Therefore, this article analyses the way in which Vigo questions, through his radical aesthetic compositions, both the very concept of poem and the processes of reading and literary interpretation. This with the aim of constituting a new way of seeing and understanding poetic work.

Keywords: Edgardo Antonio Vigo, «mathematical poem», «New Poetry Platense», Poème Mathématique Baroque, neo-avant-garde poetry.

1 Agradezco a Ana María Gualtieri, fundadora y directora del Centro de Arte Experimental Vigo, la autorización que nos brindó para el uso didáctico de las imágenes que se publican en este trabajo. También agradezco profundamente a la Dra. Ana Bugnone por su guía durante esta etapa de investigación. 


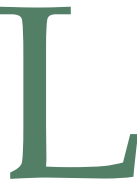

a primera vez que Edgardo Antonio Vigo presentó un «poema matemático» fue en una exposición colectiva realizada el 23 de abril de 1966 en el Bar Mimo de Buenos Aires. Sin embargo, no fue hasta el 18 de julio de ese mismo año cuando estas composiciones numéricas comenzaron a cobrar una verdadera relevancia para la crítica de su momento ${ }^{2}$. Para la composición que se expuso en la Facultad de Ciencias Médicas de la Universidad Nacional de La Plata, el artista platense diseñó un conjunto de signos numéricos y señalamientos que estaban enmarcados, cada uno por separado, dentro de distintas figuras geométricas (figura 1). Como podemos apreciar, dicha propuesta estética comienza a establecer el universo poético que Vigo desplegará a finales de los años sesenta y principio de los setenta: al geometrizar ciertos signos abstractos, el artista platense cuestiona los cánones impuestos por la tradición literaria. Esto se debe a que uno de los objetivos primigenios de los «poemas matemáticos» es la ruptura de los límites existentes entre arte y literatura; aspecto que se consigue al implementar figuras geométricas como si fueran signos gráficos.

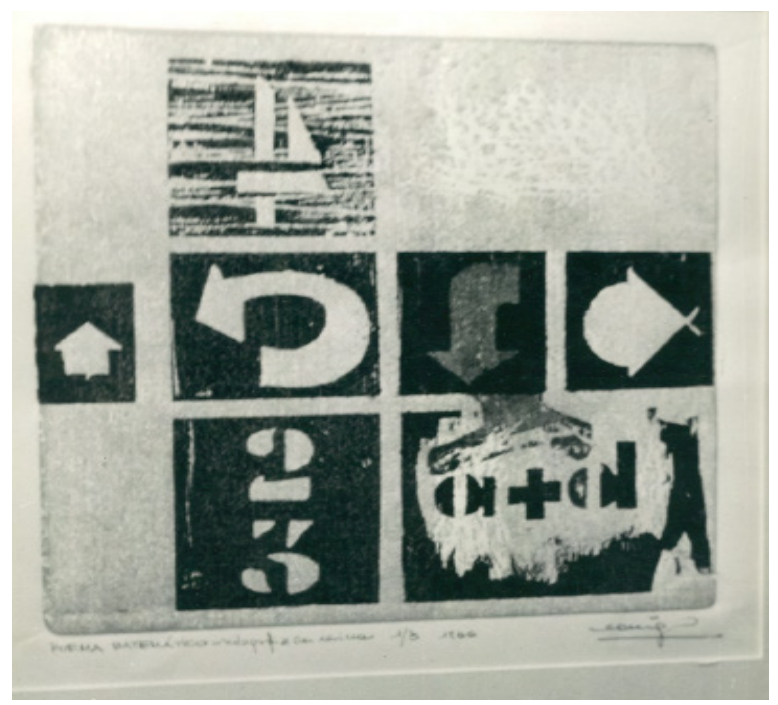

Figura 1: E. A. Vigo, «Poema matemático» (1966).

2 Para esta fecha en concreto, Al Ginzburg decidió coordinar una pequeña exposición dentro de la Facultad de Ciencias Médicas de la Universidad Nacional de La Plata, bajo el título de Los Nuevos Imagineros Argentinos. La idea central del evento era presentarle al público los innovadores proyectos estéticos que estaban realizando algunos de los jóvenes artistas platenses de la época. 
De hecho, parte de estas indagaciones sobre el acto literario ya Vigo las había llevo a cabo, precisamente, en el primer número de la revista Diagonal Cero (1962-1969)3. En dicho número, el artista platense plasma como objeto poético una pequeña xilografía (figura 2$)^{4}$. Lejos de todo, la elección de esta técnica resulta ser muy significativa, ya que a partir de esta obra no sólo apreciamos el carácter multidisciplinar que desarrollará Vigo a lo largo de su proyecto poético, sino que además podemos comprender gran parte del posicionamiento estético del autor. Para el artista argentino, como bien se puede visualizar tanto en la xilografía como en los «poemas matemáticos», un poema se constituye a partir de un texto, una imagen o una combinación de ambos signos. De tal manera que el acto poético, siguiendo esta lógica de pensamiento, se transforma en un objeto sígnico de representación; es decir, pensar la imagen como si fuera una palabra escrita. Aspecto que nos da la pauta para dilucidar el proyecto estético que Vigo va consolidando por medio de sus «poemas matemáticos»; lo que el autor denomina como «Nueva Poesía» 5 .

\footnotetext{
3 Diagonal Cero fue una revista creada y dirigida por el propio Vigo. La revista se publicó de 1962 a 1969, contando con un total de 28 números. Desde un principio, a diferencia de sus antecesoras WC (1958-1960) y DRKW 60 (1960), dicha revista se enfocó directamente en el universo poético. Por ello, la publicación misma se transformó con el correr del tiempo en un campo de experimentación literaria. Al respecto, Fernando Davis menciona lo siguiente: «Desde las páginas de Diagonal Cero [Vigo] puso en circulación poesía latinoamericana, manifiestos y ensayos, crónicas sobre la situación de las artes en La Plata, poesía experimental y ediciones de xilografías. Asimismo, en torno a su revista Vigo movilizó otros proyectos editoriales y colectivos, desde exposiciones de artistas plásticos y poetas, a la publicación de carpetas de grabado xilográfico y de "objetos poéticos" múltiples. "Diagonal Cero" no fue sólo una revista, sino también el nombre de un sello editorial y el de un «movimiento»-integrado por el mismo Vigo- de artistas plásticos y poetas visuales» (2014: 47).

4 En este punto, debemos mencionar que Vigo se tituló como Profesor de Dibujo en la Escuela de Bellas Artes de la Universidad Nacional de La Plata. Este aspecto es trascendental, puesto que tanto la visión como el trabajo literario de este poeta se deriva, como podemos observar, de las artes plásticas.

5 El término de «Nueva Poesía» fue acuñado por Vigo en el número veinte de la revista Diagonal Cero (diciembre de 1966). En dicho número, el poeta argentino constituyó, junto con el grupo artístico «Diagonal Cero» (compuesto por Alfredo Andrés, Daniel Barros, Calderón Pando, Jorge de Luján Gutiérrez, Jorge Pérez Osorio, Ismael Calvo Perotti, Lucio Loubet, Omar Gancedo y Luis Pazos), todo un conjunto de poemas visuales radicales (entre los que estaban los "poemas matemáticos») a los que denominó con el título de «Nueva Poesía Platense».
} 


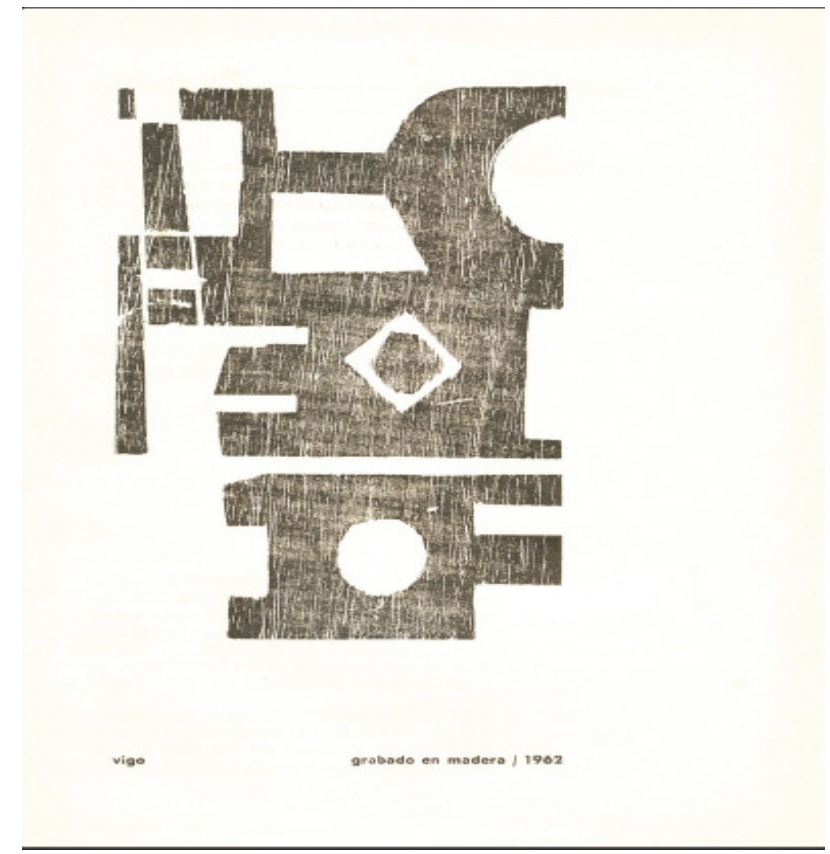

Figura 2: E. A. Vigo, «Grabado en madera» (1962).

Ahora bien, meses más tarde, el 21 de octubre de 1966, Vigo volvió a participar (esta vez como miembro de honor) en una exposición colectiva. Entre las múltiples xilografías que el artista argentino presentó en la biblioteca Benito Lynch de la ciudad de La Plata, se destacó por mucho otro «poema matemático». Independientemente del impacto visual que generan en los espectadores, lo interesante de las composiciones estéticas del artista platense es la manera en la cual constituyen una visión distinta dentro del universo literario: transformar los objetos plásticos en elementos poéticos. Esto se debe a que cada una de las propuestas publicadas por Vigo tiene como objetivo primordial la renovación del lenguaje poético vía la conformación de una nueva significación semántica: poner en un mismo nivel de configuración visual tanto la imagen como la palabra escrita. En ese sentido, este ensayo trata de evidenciar los diversos mecanismos estéticos que Vigo emplea en sus «poemas matemáticos» con la finalidad de establecer un proyecto artístico que no solo trastoca la estructura convencional del poema, sino que también cuestiona y desarticula los procesos tradicionales de análisis e interpretación que imponen las instituciones hegemónicas dentro del campo literario. Para ello, nos centramos principalmente en los planteamientos estéticos 
La «poesía matemática» de Edgardo Antonio Vigo: el poema como «intención»...

de Julia Kristeva, Alain Badiou y Josu Landa. Si bien varios críticos y académicos argentinos, como lo son Ana Longoni, Silvia Dolinko, Fernando Davis, María de los Ángeles De Rueda, Ornela Barisone y Ana Bugnone, han abordado -muchas veces de manera parcial- los «poemas matemáticos» de Vigo, la gran mayoría de ellos lo han hecho desde el ámbito de las artes plásticas ; de ahí que la crítica literaria hispanoamericana todavía no haya podido «reconocer» estas prácticas artísticas como parte de su corpus poético ${ }^{7}$. Por consiguiente, la relevancia de este trabajo parte del acercamiento literario que le realizamos al proyecto estético del artista platense.

Como hemos mencionado anteriormente, los «poemas matemáticos» inauguran, en el número veinte de la revista Diagonal Cero (diciembre de 1966), el proyecto estético denominado como la «Nueva Poesía Platense». Para la portada de dicho número, los editores eligieron un nuevo «poema matemático» de Vigo, el cual, a diferencia de sus antecesores, denota un armado discursivo diferente: ya no existe una geometrización bien estructurada de cada uno de los elementos de la composición, sino que ahora dichos signos se encuentran visualmente entremezclados (figura 3). Este cambio radical en la estructura interna de los «poemas matemáticos» deja en claro el cuestionamiento tanto a la forma como a la intención misma del poema (aspecto que Vigo ya venía confeccionando en algunas de sus xilografías y esculturas mecanizadas denominadas como Relativuzgir's ${ }^{8}$ ): para el artista platense, el

\footnotetext{
6 Destacamos, sobre todo, los siguientes trabajos: «Edgardo Antonio Vigo, vanguardia y contracultura en los años setenta» (2012) de Silvia Dolinko, «Poéticas oblicuas. Grabado, cuerpos y poesía en Diagonal Cero» (2014) de Fernando Davis, «La escapada de la línea: Edgardo Antonio Vigo y la construcción de la poesía visual como género» (2014) de Ornela Barisone, «Utopías realizables: E. A. Vigo y el arte expandido en La Plata» (2018) de María de los Ángeles De Rueda y los libros Vanguardia y revolución: Arte e izquierdas en la Argentina de los sesenta-setenta (2014) de Ana Longoni y Vigo. Arte, política y vanguardia (2017) de Ana Bugnone.

7 Es importante recalcar que el proyecto estético de Vigo, a pesar de ya ser reconocido dentro de las esferas artísticas nacionales e internacionales, todavía sigue siendo un fenómeno «relegado» para la crítica literaria actual. Y únicamente aparece en los ensayos académicos como mera referencia histórica (sin tocar a profundidad el eje central de sus propuestas poéticas). Por ello, destacamos los trabajos de Fernando Davis, Ornela Barisone, Óscar Galindo y Pauline Medea Bachmann, quienes vislumbran las obras de Vigo a partir de ciertas conceptualizaciones provenientes de la poesía visual.

8 Varias de las conceptualizaciones estéticas que Vigo constituye en los «poemas matemáticos» son, en realidad, reactualizaciones de los mecanismos artísticos desarrollados en los Relativuzgir's (1957-1960): por un lado, dichas obras parten de una superposición de elementos visuales (situación que el artista platense retoma de las obras dadaístas de Marcel Duchamp, Francis Picabia y Kurt Schwitters) y, por el otro, su construcción mecanizada obedece a postulados provenientes de las ciencias exactas (física/matemática/ingeniería) (Gradowczyk, 2008: 43). Con ello, podemos comprender el carácter multidisciplinar que Vigo va conformando en su proyecto poético.
} 
acto poético no debe limitarse únicamente a la dimensión pragmática de la lengua, ya que en esta se ejerce lo que Julia Kristeva nombra como la «función simbólica del lenguaje».

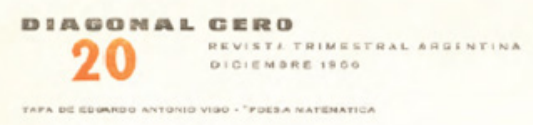

NUMERO DEDICADO A LA NUEVA POESIA PLATENSE

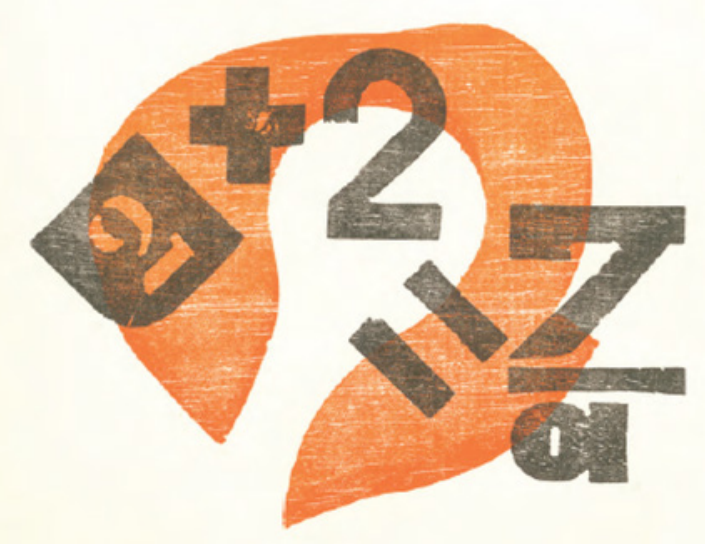

Figura 3: E. A. Vigo, «Poema matemático» (1966).

Para la crítica búlgara, la «función simbólica» debe ser entendida como la dimensión coercitiva y socializante que subyace en el lenguaje mismo: «Solo al precio de la represión de la pulsión y de la relación continua con la madre se constituye el lenguaje como función simbólica» (1981: 263). Precisamente, dicho elemento es lo que permite la constitución de un código estructurado y estructurante que hace posible un proceso de comunicación convencional. De ahí que Kristeva decida emplear el término de «significancia» (concepto tomado del psicoanálisis) en vez de «significado» (concepto usado por el estructuralismo para referirse al proceso de unir al significante con el significado). La razón fundamental de este cambio de términos es que el concepto de «significancia» configura una perspectiva del signo que va mucho 
más allá del simple proceso de unificar al significante con el significado. Por ello, Manuel Asensi Pérez, con base en los estudios de Kristeva, define a la «significancia» como «[...] un trabajo de producción y transformación que desemboca en la ausencia de sentido o, lo que es prácticamente lo mismo, en la multiplicidad de sentidos» (2003: 298). Esta acción provoca una crítica directa a la idea convencional de signo; lo que permite entender al texto como una «productividad»: «Para nosotros, el texto no es un objeto estético, literario, etc.... Es una operación trans-lingüística que, aunque se produce en la lengua, es irreductible a las categorías conocidas del lenguaje de la comunicación -objeto de la lingüística-» (Kristeva, 1976: 279) ${ }^{9}$.

Estos planteamientos críticos desarrollados por Kristeva resultan ser sumamente trascendentales para comprender el proyecto estético de Vigo. Esto se debe, principalmente, a que los «poemas matemáticos» rompen con la significación única del poema con el claro propósito de potenciar los múltiples elementos discursivos contenidos dentro de ellos. Al configurar en un mismo nivel sintáctico tanto a la imagen como a la palabra escrita, las propuestas visuales del artista platense consiguen desajustar la «función simbólica del lenguaje», puesto que el poema se transforma en una "productividad textual», en donde todos los signos adquieren una potencialidad como unidades semánticas; propiciando así la constitución de una multiplicidad de sentidos. De hecho, esto es un aspecto que Vigo retoma de Julien Blaine, ya que en uno de sus ensayos el artista francés señala que todos los elementos vertidos dentro de un dispositivo (incluido el dispositivo mismo) deben ser considerados como «escritura» (1967: 9). En consecuencia, partiendo de estas conceptualizaciones estéticas, podemos afirmar que todo signo gráfico (ya sea una imagen o una palabra escrita) presente dentro de los límites del poema puede ser visualizados como un «texto en sí mismo»:

«Un» no puede ser en ningún caso musical, «U» luego «n»o «U»+ «n»o cualquier «Un» disociado se convierte en música. «U» es una primera imagen. «n» una segunda imagen, una primera palabra, una segunda palabra, un primer grupo de letras, un segundo grupo de letras... disociaciones que se convierten en nuevas unidades. (Blaine, 1967: 5)

\footnotetext{
9 Es importante recalcar que Kristeva prefiere el término de texto en vez de literatura, ya que al no emplear este último «[...] nos negamos a limitar nuestro a una derivación estética, y consideramos los textos como cristales de la significancia en la historia» (Kristeva, 1976: 276).
} 
Estas nuevas unidades semánticas descritas por Blaine terminan por convertirse en nuevos significantes; lo que provoca que el poema se expanda mucho más allá de su simple finalidad comunicativa, es decir, la constitución de un solo sentido poético. Por tal motivo, el poema ya no surge de un proceso sumativo entre los distintos elementos vertidos en él (la conformación de cadenas de oraciones escritas), sino que la conjunción del poema deviene cuando cada uno de los signos visuales se transforma en un catalizador de nuevos significantes (desarrollar lo que Kristeva denomina como la «significancia»). Situación que podemos apreciar, sobre todo, en el «poema matemático» de la portada número veinte de Diagonal Cero. En dicha propuesta, la suma de las unidades «2»y «2» no dan «4», como sucedería dentro de un proceso de razonamiento lógico y lineal; por el contrario, el resultado final de la ecuación es una expresión algebraica (7/a). Gracias a este resultado, la poética de Vigo se revitaliza tanto en su forma como en su significación semántica, puesto que la subversión que se le hace al campo del razonamiento lógico permite que el poema se catapulte fuera de los parámetros de lectura convencionales. De tal manera que los múltiples elementos que integran la composición visual logran desestabilizar (en su conjunto) las ideas preconcebidas de lo que significa un poema.

Esta «complejidad visual» que Vigo constituye en su propuesta estética (exponer una serie de signos matemáticos) ayuda a que el acto poético vaya más allá de los terrenos de la escritura; acción que cuestiona directamente el canon literario impuesto por la tradición misma. No debemos olvidar que, desde la antigüedad, la idea de poesía siempre ha estado asociada a una forma discursiva (por lo general en verso) que es escrita y cantada. Al respecto, Pere Ballart menciona que

[...] el poeta (que no era conocido con este nombre, sino con el de aedo, esto es, cantor), en el marco espectacular de un altar o escenario, declamaba sus versos o los cantaba, a menudo con la actuación simultánea de unos bailarines, acompañándose con un instrumento musical, que generalmente era la lira - hecho que explica la habitual denominación de lírica, que ha pervivido en el tiempo más allá de la postergación de estos canales orales y que, por tanto, no tiene hoy otro valor que el metafórico - (con todo, el uso actual del término contempla todavía una parte del sentido original: con frecuencia nos referimos a la ópera, drama musical cantado, como «el género lírico», y la palabra inglesa lyrics sigue designando cualquier letra de canción) (2005: 55-56). 
Apelando a estos parámetros que surgen en la Grecia Antigua, la tradición literaria ha constituido un concepto de poema que gira en torno a la palabra escrita y, casi siempre, versificada; aunque esto último se ha ido modificando con la inclusión de la prosa poética y el poema en prosa (Ballart, 2005: 64). En ese sentido, dejando de lado la estructura formal de los discursos poéticos (si son escritos en prosa o en verso), lo realmente trascendental de este modo de ver y concebir el poema es, justamente, su vinculación al terreno de la escritura: por lo general, no se puede pensar en un tipo de poesía que se construya fuera de las dimensiones convencionales de la hoja en blanco. De hecho, el crítico Josu Landa comenta que «[...] el poema aparece, en primer término, como una agrupación de palabras y expresiones» (2002: 43). Inclusive, los propios juegos de palabras que desarrollan los caligramas e ideogramas, así como la radicalidad visual de los poemas concretos y constelaciones, continúan ligados a una cuestión puramente escrita ${ }^{10}$. Por ende, para Ballart, el cambio más trascendental y significativo que ha tenido el poema dentro de la tradición literaria es «[...] el paso de una lírica oral a otra escrita» (2005: 62).

Esta cuestión descrita por Ballart es sumamente vital, ya que deja en claro la visión aristotélica que aún persiste dentro del canon poético: pensar el poema desde los conceptos de forma (el verso) y contenido (un mensaje comunicable por medio de la palaba escrita); lo que para Landa significa el «encasillamiento» y «mitificación» de un tipo de texto cuya presencia externa e interna es ampliamente reconocible por el público convencional (2002: 45). En consecuencia, los «poemas matemáticos» de Vigo, en esa busca por establecer la «significancia» descrita por Kristeva, terminan por trastocar la forma canónica que ha impuesto la propia tradición literaria. En otras palabras, el hecho de presentar a la imagen como el principio fundamental del poema (ver a los elementos visuales como si fueran palabras escritas) se contrapone directamente a lo que la crítica literaria ha denominado como «lo verbal» (Landa, 2002: 77; Aguilar, 2003: 117-118; Hernández Espinosa y Palma Castro, 2017: 218), que no es otra cosa que el poema escrito con palabras.

Con base en lo anterior, podemos decir que la «potencialidad significativa» de los «poemas matemáticos» de Vigo (la ruptura con el aspecto «verbal» del

10 Yolanda Guerra Macías afirma que, independientemente de los procedimientos y las técnicas empleadas por los autores, el elemento fundamental de las composiciones visuales (como es el caso de los caligramas e ideogramas) sigue siendo la palabra escrita (2011: 73). De igual manera, Gonzalo Aguilar, en su estudio sobre la poesía concreta brasileña, enfatiza que gran parte del proyecto del grupo "Noigandres" siempre estuvo ligado a los terrenos de lo puramente verbal (2003: 117-118). 
poema) subyace en el uso constante de números, formas y colores. Por consiguiente, a diferencia de lo que señala Ornela Barisone, dichos elementos no están sustituyendo a la palabra escrita; por el contrario, lo que en realidad están haciendo es potenciar a los signos gráficos como significantes activos ${ }^{11}$. Un ejemplo claro de ello es el poema «II ${ }^{\circ}$ Teorema Fundamental» (1966), en donde Vigo presenta en el lado izquierdo de la composición, de manera vertical, tres letras «a» mayúsculas elevadas a la cuarta, segunda y primera potencia, respectivamente; mientras que, en el lado derecho, expone dos ecuaciones algebraicas, sin aparente resolución (figura 4). Partiendo de la estructura interna del poema, podemos advertir que la palabra (en este caso la letra «a») pierde su esencia comunicativa (ser la primera letra del alfabeto latino) con el objetivo de adquirir una nueva significación como signo matemático (actuar como un valor constante dentro de las ecuaciones algebraicas). Sin embargo, al ser precisamente la letra «a» un valor constante pero indefinido, las ecuaciones acaban por no tener una aparente resolución, dando como resultado un «teorema fundamental» que no sirve para «nada», es decir, que no es demostrable. Es en este punto, cuando la palabra misma se transforma en un significante activo que da pie a un proceso «imaginativo» por parte del lector, ya que lo único demostrable dentro de la fórmula es, paradójicamente, la indeterminación de «a». Por tal motivo, el receptor se ve sumergido dentro de una «irracionalidad» para sus parámetros de lectura convencionales, puesto que el procedimiento lógico de las matemáticas se ve desarticulado, en la medida en que las ecuaciones se van volviendo irresolubles.

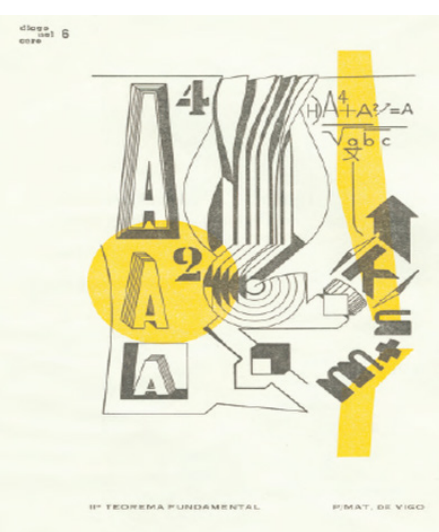

Figura 4: E. A. Vigo, «II Teorema Fundamental» (1966).

11 En su estudio, Barisone afirma que, dentro de la «parataxis matemática» de Vigo, «El número remplaza a la letra o se funde compositivamente con ella» (2014: s/p.). 
Ahora bien, esta composición, como su propio nombre lo indica, actúa como una especie de teorema fundamental para comprender la visión estética de Vigo. Para el artista platense, el poema puede ser entendido como un campo de experimentación formal que permite revitalizar al signo gráfico (tanto a la imagen como a la palabra escrita). De tal manera que la poética de Vigo no es una concatenación de palabras cuya única finalidad es «revelarle» algo al lector, sino más bien es una serie de significantes activos que desvirtúan la idea misma de una interpretación clara y única (la «significancia» de Kristeva). A partir de ello, podemos dilucidar un aspecto fundamental de la «poesía matemática», y que será trascendental para los posteriores trabajos estéticos de Vigo: la poesía como «intención» y no como forma y contenido (el principio aristotélico señalado por Ballart). Si en una primera instancia hemos mencionado que el proyecto estético del artista platense intenta constituir una multiplicidad de sentidos, también debemos puntualizar que esta búsqueda por establecer la «significancia» de Kristeva desemboca en un acto poético que trata de nulificar su propia existencia. Es decir, los «poemas matemáticos» de Vigo acaban por no ser "poemas matemáticos», puesto que sus estructuras discursivas contradicen la supuesta «intencionalidad» del poema: por un lado, el término «matemático» se nulifica en el preciso momento en el que las ecuaciones algebraicas parecen no tener una respuesta lógica; y por el otro, el concepto de «poema» se desvirtúa cuando el lector tiene un conflicto visual con sus parámetros de lectura convencionales (no ver una estructura compuesta por una concatenación de palabras). Por consiguiente, la poética de Vigo no responde a una estructura e interpretación determinada, sino más bien a las «intenciones significativas» que esta guarda con los múltiples elementos que la componen. De ahí la trascendencia de que Vigo emplee ecuaciones algebraicas irresolubles como elementos desestabilizadores dentro de sus poemas.

Al configurar sus propuestas estéticas como textos poéticos que no se adecuan a estructuras y formulas prestablecidas por la tradición literaria, los «poemas matemáticos» de Vigo desarticulan su propia estructura lógica para centrarse exclusivamente en la «intención significativa» del texto. Es aquí cuando la participación activa del lector comienza a jugar un papel fundamental dentro de las composiciones visuales del artista platense: al darnos cuenta de que las ciencias exactas (en este caso las matemáticas) acaban por no dar una respuesta «lógica», uno como lector pasa por un momento de incertidumbre, lo que provoca que el poema quede suspendido en una especie de «posibilidad»; generando con ello la multiplicidad o ausencia de sentido. 
Este aspecto se puede observar con mayor detalle en el «Poema matemático fallido» (1966), en donde, debido al tipo de estructura caótica que se maneja, no se sabe con exactitud cuál es el supuesto «error» del poema (figura 5). En ese sentido, apelando al título de la obra, el lector empieza a dudar acerca de sus procedimientos analíticos, hasta el punto de que él mismo tiene que aceptar la posibilidad de una supuesta «falla» en el poema. Y es justamente a través de esta ironía cuando la «intención significativa» de los «poemas matemáticos» adquiere una mayor relevancia dentro de la obra poética de Vigo: lo importante no es analizar lo que dice el poema (la «intención comunicativa»), sino más bien lo que el lector dice sobre el poema (la «intención significativa»). Por tal motivo, con base en estos planteamientos, podemos decir que la «significancia» de los «poemas matemáticos» se activa a partir del estupor que tiene el lector al enfrentarse a un poema que no tiene «solución»; es decir, un poema que no puede «leerse» en los mismos términos que demanda la tradición literaria. Esto es algo que Ana Bugnone también ha enfatizado a la hora de hablar sobre la poética de Vigo:

Vigo desarma la escritura a partir de la poesía visual, colocando signos que pierden racionalidad y funcionalidad, palabras aisladas. Compone una poesía que no solo desestructura las reglas del lenguaje literario, sino que además genera una percepción corrida de su eje normal: una poesía que no puede leerse. Esto implica un desencaje del orden que representan las reglas de la lectura, la escritura y la percepción, así como del significado de esas palabras, letras y números en la estructura de la lengua y la matemática. La poesía visual es, entonces, una ruina de sentido (2011: 259).

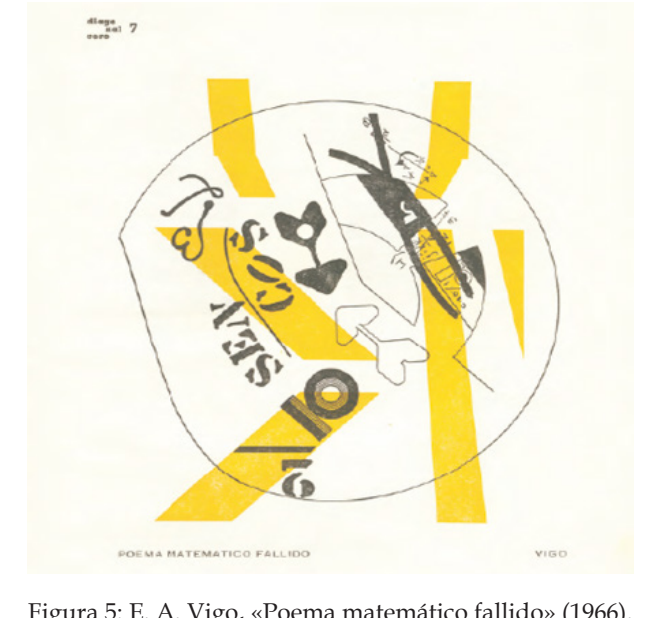


Esta cuestión acerca de la «intención significativa» del texto expresada en los «poemas matemáticos» se convierte en un aspecto vital para el proyecto estético de Vigo. Al ser propuestas visuales que desarticulan el concepto tradicional de poema, las expectativas lectoras se transforman en una pieza clave para la concreción final de los actos poéticos. En este punto, el desencaje del orden establecido que señala Bugnone acaba por ser una cuestión mucho más profunda de lo que se aprecia en una primera instancia. Si como dijimos anteriormente, la «función simbólica de la lengua» actúa como un elemento que «fosiliza» a la palabra (generarle al signo una estructura fuertemente coercitiva y socializante), entonces, la «significancia» del poema subyace en lo que el propio lector dice sobre la propuesta visual. Con ello, el proyecto estético de Vigo no solo reposiciona al lector dentro de una dinámica altamente participativa (ser el eje central de los poemas), sino que además logra establecer un tipo de poema que se «nulifica» a sí mismo (ser un texto que «no puede» ser «analizado» e «interpretado» de una forma convencional); lo que permite la liberación de los signos gráficos como significantes activos.

Esta forma de entender el poema por parte de Vigo resulta ser, para Alain Badiou, la génesis de todo acto poético: «[...] el poema no es ni una descripción ni una expresión. Tampoco es una pintura emotiva de la extensión del mundo. El poema es una operación» (2009: 76). Tomando como punto de referencia la obra de Stéphane Mallarmé, el filósofo francés señala que la «potencialidad» del poema radica en lo «innombrable», que no es otra cosa que la creación de palabras sin sentido y la constitución de una forma poética fuera de la lógica establecida (2009: 71-72). Gracias estas afirmaciones, podemos comprender con mayor precisión la visión estética de Vigo: la intención primigenia de los «poemas matemáticos» es liberar al texto de su funcionamiento rutinario (la comunicación lineal con el lector; es decir, su «función simbólica»). Por consiguiente, los trabajos visuales que componen el proyecto estético del artista platense buscan establecer una forma poética que disuelva tanto los límites del poema y del lenguaje como las convenciones sociales y los procedimientos tradicionales de la interpretación literaria. De tal manera que la esencia misma de estas poéticas radicales desarrolladas por Vigo se corresponde a un modelo que, como bien dice Badiou, no quiere ser «interpretado» de la forma convencional, sino más bien «comprendido» en toda la extensión de la palabra: 
El poema se concentra en la disolución del objeto en su pureza presente, es la constitución del momento de esa disolución. Aquello bautizado como «hermetismo» no es otra cosa que lo momentáneo del poema, momentáneo que solo es accesible por medio de una oblicuidad, oblicuidad que señala el enigma. El lector debe entrar en el enigma para alcanzar el punto momentáneo de la presencia. Si no, el poema no opera [...] El poema de Mallarmé no nos pide que lo interpretemos, y no existe ninguna clave. El poema pide que entremos en su operación y el enigma es ese pedido en sí mismo. La regla es simple: entrar en el poema, no para saber de qué habla, sino para pensar qué pasa en él. Como el poema es una operación, también es un acontecimiento. El poema tiene lugar. El enigma superficial es la indicación de ese tener lugar: nos ofrece un tener lugar dentro de la lengua (Badiou, 2009: 76).

Como hemos observado a lo largo de este análisis, muchos de los planteamientos estéticos de Vigo que giran en torno a la desarticulación del campo comunicativo (la «no interpretación» por medio de los estatus prestablecidos por la tradición literaria) se asemejan por mucho al proceso semiótico desarrollado por Kristeva: por un lado, la desarticulación de la «función simbólica de la lengua»y, por el otro, la recuperación del denominado «balbuceo lingüístico». Si para la crítica búlgara la «función simbólica» actúa como el «Nombre del padre», entonces todo aquello que se excluye del proceso comunicativo debe ser considerado como el «Cuerpo de la madre». Para Kristeva, lo materno se compone de las pulsiones lingüísticas que corresponden a una etapa previa de la significación: «[...] previo a la aparición del lenguaje, se manifiesta en los niños pequeños la renuncia al paraíso materno y a la satisfacción inmediata de la demanda. Es preciso abandonar a la madre y ser abandonado por ella para ser recogido por el padre y para hablar» (1986: 66). Esto resulta ser trascendental, puesto que los «poemas matemáticos» tienen como objetivo primario la constitución de un lenguaje poético que se contrapone a la idea canónica de lo que significa comúnmente un poema.

En ese sentido, la apuesta estética de Vigo busca desestabilizar las diversas formas comunicativas impuestas por las instituciones hegemónicas: desde el cuestionamiento del aspecto «verbal» del poema (poner a la imagen como el principio fundamental del acto poético) hasta la propia experimentación de los dispositivos tradicionales (el juego visual e interactivo que se constituye alrededor de la hoja en blanco). Por ende, las propuestas visuales del artista 
platense se distancian de otras manifestaciones literarias que poseen la «no comunicación lineal» con el lector como eje central de composición estética; como es el caso de la poesía hermética y el dificultismo poético ${ }^{12}$. Con base en ello, podemos precisar que la «intención significativa» del poema no se vincula directamente con el enrarecimiento del lenguaje poético (el dificultismo); por el contrario, dicho concepto parte del cuestionamiento y la desarticulación que se le hace a los múltiples mecanismos ideológicos que intervienen en la conformación de los discursos comunicables (la «significancia» descrita por Kristeva).

A partir de esta «intención significativa» del poema, Vigo comienza a perfilar la idea de una «estética de la participación»: hacer que el lector mismo se convierta en el motor principal para la renovación de la forma poética. Prueba de ello, es la publicación del libro De la poesía/proceso a la poesía para y/o a realizar (1969), en donde el artista platense presenta al receptor como el eje primordial de las poéticas radicales (1969: 3). La razón de esta «obsesión» especial de Vigo por la participación activa del lector tiene mucho que ver con los planteamientos estéticos de la época. Independientemente de los estudios de recepción literaria inaugurados por Hans Robert Jauss en la Universidad de Constanza (1967) y la tan famosa «mort de l'auteur» de Roland Barthes (1968), debemos tener en cuenta que uno de los principios fundamentales de la Vanguardia (y, por ende, de la Neovanguardia) es la «eliminación» del público pasivo: «El dadaísmo, el surrealismo, el futurismo, reclamaron una participación más activa por parte del espectador, para provocarlo y generar su reacción ante lo que se estaba realizando» (Bugnone, 2017: 74). Para Vigo, el lector no está allí para ser un mero «observador», un simple «receptáculo» de los signos impuestos por el autor; por el contrario, su sola presencia ayuda a la constitución de nuevas formas y significaciones. De ahí que el artista platense sustituya el concepto de «autor» por el de «programador» (1969: 7), puesto que la función de este último se limita exclusivamente a encaminar al receptor para que este desarrolle por sí mismo su pensamiento reflexivo (su propia interpretación de lo que puede significar el poema).

12 En el caso específico del dificultismo, este puede definirse como la creación de formas novedosas que desafíen y discutan los límites del lenguaje poético. Por lo cual, sus principales mecanismos de construcción giran en torno al concepto de extrañamiento propuesto por Viktor Shklovski (Palma Castro, 2016: 223-224; Higashi, 2018: 42-43). 
Es bajo esta nueva perspectiva crítica cuando Vigo decide publicar, con ayuda de sus amigos J. F. Bory y Brian Lane, el libro Poème Mathématique Baroque (1967) en la editorial francesa Contexte ${ }^{13}$. En términos generales, el poemario se compone de tres pequeños cartones rectangulares, a los cuales Vigo les realizó algunos cortes y dobleces con la finalidad de que el lector pudiera mover ciertos pedazos del soporte plástico. Por lo tanto, partiendo de esta concepción estética, la estructura de cada uno de los poemas se compone de la siguiente manera: son dos rectángulos de cartón pegados entre sí, los cuales poseen una pequeña abertura en donde el artista platense coloca hojas de colores (un color para cada composición: rojo, azul y amarillo). En la primera propuesta, aparecen dos tipos de recortes en el centro del poema: tres pequeñas aberturas circulares, que muestran, sin mover el dispositivo, la hoja de color rojo que funciona como el trasfondo del poema y dos cortes rectos perpendiculares, que permiten la movilidad del objeto (figura 6). En este punto, el lector puede manipular los triángulos de cartón sobresaliente, que se originan de los recortes perpendiculares, posibilitando así la transformación del poema en un objeto plástico que interactúa con el espectador, a través de la conformación de determinadas figuras geométricas.

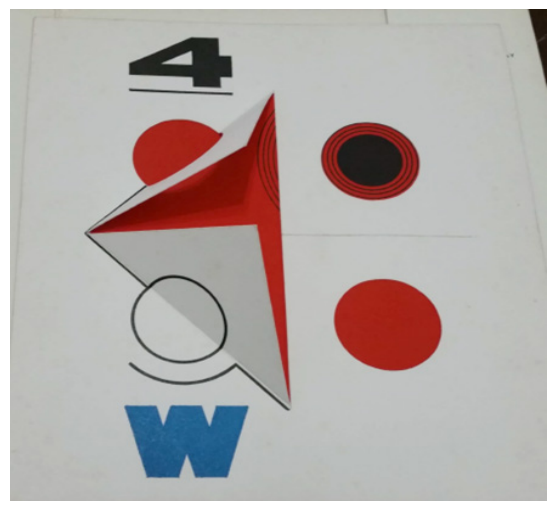

Figura 6: E. A. Vigo, «Sin título» (1967).

13 Fernando Davis afirma que «Vigo había tomado contacto con los editores de Contexte en 1966. Como se ha mencionado, Bory publicaba entonces, junto con el poeta Julien Blaine, la revista Approches, también dedicada a las manifestaciones de la nueva poesía. En 1968 el número 3 de Approches, dedicado a la poesía visual, incluyó poemas de Ginzburg, Pazos y Vigo. Un año antes Diagonal Cero presentaba sendos ensayos de Bory y Blaine y este último convocaba a Pazos y a Vigo a participar en el Premier inventaire de la poésie elementaire [Primer inventario de la poesía elemental], en la galería Denise Davy de París. Allí Vigo expuso los Poéme [sic.] Mathématique Baroque, mientras que Pazos presentó su "libro-objeto" El Dios del Laberinto, una botella con un poema enrollado en su interior» (2014: 59-60). Ahora bien, el tiraje de los Poème Mathématique Baroque fue alrededor de unos setecientos ejemplares, de los cuales treinta fueron enviados a Vigo como "pago». Un año después, debido a la popularidad del poemario, la editorial francesa Agentzia realizó una segunda edición del libro. 
El segundo poema parte de una estructura similar: Vigo vuelve a presentar los mismos tipos de recortes; es decir, aberturas circulares y líneas perpendiculares. No obstante, la diferencia con respecto al primero radica precisamente en la intencionalidad que tiene con el lector: el artista platense coloca en el centro del dispositivo una de las aberturas circulares, mientras que la segunda es puesta en la esquina central derecha, formando así un semicírculo. Asimismo, Vigo recorta dos líneas verticales y una horizontal, lo que propicia que toda la estructura central del soporte pueda levantarse a modo de rectángulo (figura 7). Como se puede observar, aquí existe una variación formal con el primero, puesto que el autor invierte el número de círculos y líneas (de tres círculos pasa a dos y de dos líneas pasa a tres). Este cambio substancial también se aprecia en la propia finalidad de los recortes: a diferencia del primero, el artista argentino emplea la abertura central como un elemento que invita a la interacción con el objeto, ya que dicho circulo permite observar una línea negra que atraviesa el trasfondo del dispositivo, la cual, significativamente, es la misma línea que se curvea en la esquina derecha hasta ingresar debajo de la zona recortada. Al levantar el pedazo rectangular, se puede observar no solo la continuación de la línea, sino además una letra «a» mayúscula en uno de los lados ocultos de la figura geométrica (figura 8). Este descubrimiento por parte del lector acaba por resignificar al poema mismo; en otras palabras, a raíz de esta interacción, la propuesta visual se transforma tanto en un objeto plástico como en un poema que deviene simultáneamente en varias posibilidades.

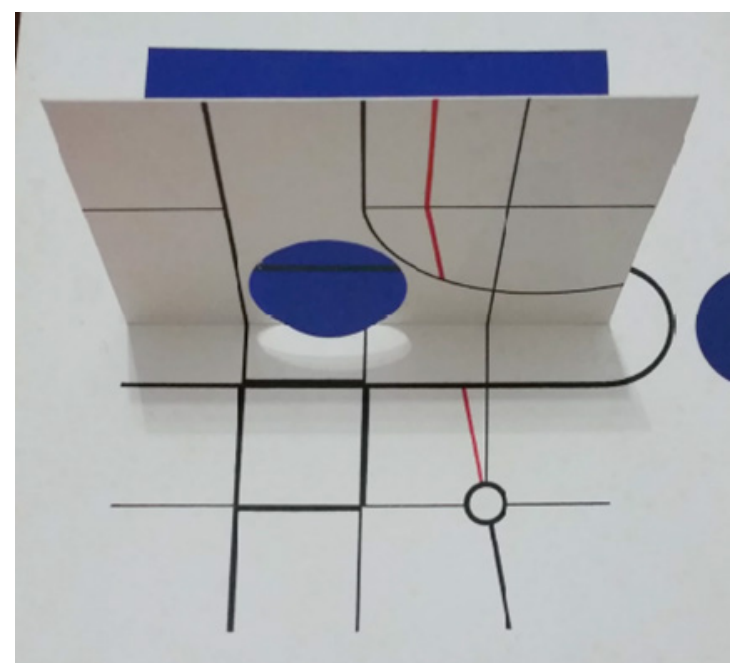

Figura 7: E. A. Vigo, «Sin título» (1967). 


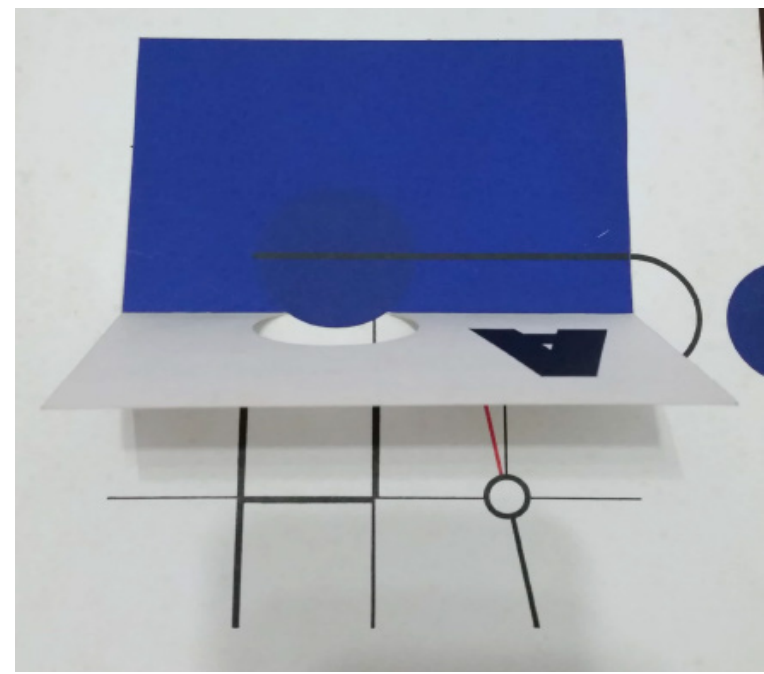

Figura 8: E. A. Vigo, «Sin título» (1967).

Ya el último poema es el menos interactivo de los tres, puesto que Vigo solo presenta en él un simple recorte diagonal en la esquina inferior derecha (figura 9). Si bien dicha abertura podría no significar un gran acontecimiento en comparación con los otros dos, también tenemos que decir que este recorte permite visualizar la interacción sensorial que ocurre en los poemas anteriores; y que debido a la manipulación que se hace de los objetos puede pasar desapercibido por el lector. La idea es que el lector pueda sentir la textura de la hoja de color amarillo (aspecto que se repite en las propuestas anteriores). Esta acción motriz pone de manifiesto una relación más palpable con el acto poético: Vigo demuestra que el poema no es algo que únicamente se ve, se lee y se escucha, sino que también se palpa (tocar el trasfondo del poema, es decir, las hojas de colores); situación que permite transfigurar a las palabras e imágenes en objetos plásticos. En consecuencia, podemos afirmar que la propuesta visual de Vigo genera un cambio radical en el acto poético: el poema pasa a ser, independientemente del dispositivo, la forma y el contenido, una experiencia que brota de la interacción con el objeto. 


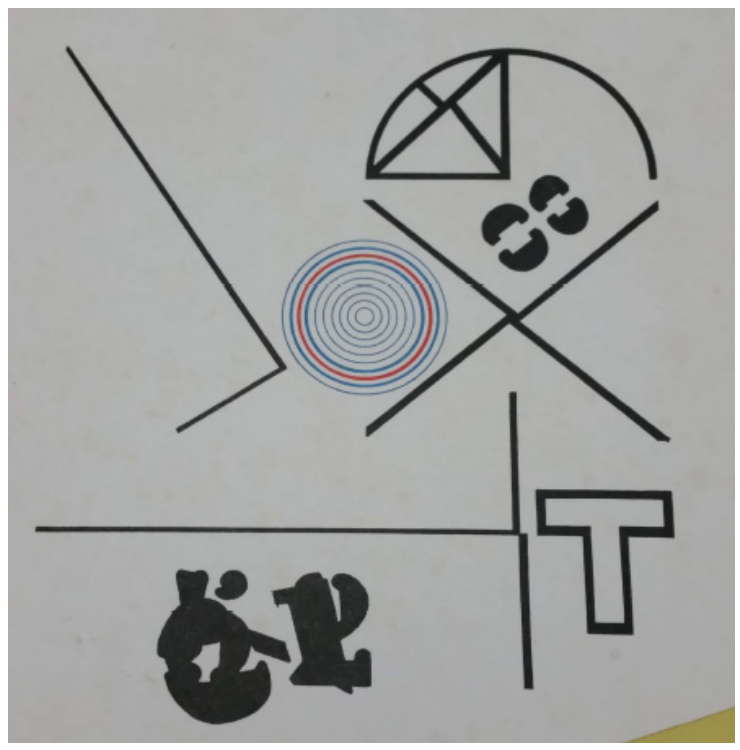

Figura 9: E. A. Vigo, «Sin título» (1967).

Como se puede visualizar, ya desde la concepción misma del texto, el poemario de Vigo representa una búsqueda por desarticular las ideas tradicionalistas que se tiene acerca del autor y el lector. Esto se debe a que los nuevos poemas de Vigo parten de un dinamismo mucho más complejo que los desarrollados en los «poemas matemáticos» anteriores: el artista platense deja de lado la saturación caótica de formas, números y palabras, para centrase únicamente en pequeños agujeros, cortes y dobleces, que permiten que los poemas adquieran una estructura en tercera dimensión. Y es a partir de esta estructura dinámica cuando la acción participativa del lector adquiere una condición mucho más privilegiada, ya que la manipulación de cada uno de los poemas da como resultado no solo una obra que deviene en otra, sino que además dichas obras que surgen se convierten en «objetos poéticos» creados por el lector mismo. En ese sentido, la idea central de los Poème Mathématique Baroque es transformar al lector en un «co-autor» de la obra; idea que Vigo desarrolla, puntualmente, en su libro De la poesía/proceso a la poesía para y/o a realizar.

Significativamente, esta nueva práctica que Vigo le sugiere al lector es uno de los diversos mecanismos artísticos que permite la desestabilización de los objetos y las formas literarias tradicionales. Al darle al lector la posibilidad de manipular cada uno de los poemas a su antojo, Vigo logra desarticular la 
estructura poética desde tres flancos: primero, el poema se convierte en un objeto palpable que interactúa físicamente con el espectador, lo que provoca que la escritura ya no sea vista como un elemento "sagrado» e «intocable»; segundo, el lector de poesía deja de ser un simple analista e interpretador de la obra para transformarse en un «constructor» más del poema, lo que da como resultado una «desacralización» de la figura de autor ${ }^{14} \mathrm{y}$ tercero, el acto poético se transforma en un elemento que ya no necesita de las palabras escritas para poder existir como tal, lo cual se confronta directamente con las formas canónicas de la poesía (el «poema verbal»). Es en este punto, cuando el poemario pasa a ser considerado como un "poema para armar»; término que Vigo empleó a principios de 1969 para referirse a todas esas propuestas visuales que «[...] deben ser «compuesto» por el público a quien se incita a quitar o agregar elementos no computado -pero sí computables en el resultado final- por el poeta» (Vigo, 1969: 3) ${ }^{15}$.

$\mathrm{Al}$ ser un grupo de poemas que deben ser «armados» por el lector, Vigo centra toda la «intención significativa» del poemario en el desajuste de los parámetros de lectura que se encargan de regular ciertas prácticas y estructuras literarias. Por consiguiente, siguiendo esta línea de pensamiento, el poemario cuestiona de manera simultánea tanto la forma poética como la figura de autor: el poema solamente se vuelve «poema» cuando el lector lo hace «suyo», es decir, lo manipula con el objetivo de crear una nueva distribución y resignificación de los elementos vertidos dentro de él. De ahí la trascendencia de que Vigo haya usado el término «barroco» para referirse a sus nuevos «poemas matemáticos ${ }^{16}$, ya que como menciona en un artículo publicado en el número

14 Al cederle el «control creativo» al lector (modificar la estructura y lectura lineal del poema), el poemario Poème Mathématique Baroque centra parte de su cuestionamiento literario en el aspecto autoral. Al igual que Michel Foucault, Vigo comprende que el autor es más bien una figura textual cuya principal función es la de darle un cierto sentido al discurso: «[...] la función autor está vinculada al sistema jurídico e institucional que rodea, determina y articula el universo de los discursos [...]» (Foucault, 1999: 343). Por tal motivo, cuando el lector manipula los poemas, lo que en realidad está haciendo es cuestionar la idea de lo que comúnmente se entiende tanto por «figura autoral» como por «obra artística».

15 Este concepto de «poema para armar» surgió a raíz de una obra realizada por Julien Blaine a finales de los sesenta. Para Vigo, lo más trascendental de este proyecto realizado por el artista francés fue la intervención de un nuevo agente para la «conclusión» de la obra: el observador-participante. Es por ello que, siguiendo esta misma fórmula, Vigo transforma sus «poemas matemáticos» en «poemas para armar».

16 Tenemos que mencionar que esta idea del «barroquismo visual y poético» es un concepto que Vigo retoma de Haroldo de Campos. Si bien para el artista platense la hoja en blanco deja de ser un dispositivo adecuado para la continuación de su proyecto literario, lo que sí comparte con el grupo de los concretistas brasileños es esta búsqueda constante por romper la linealidad de la poesía: «[...] el grupo brasileño trabajaba con elementos más complejos y menos fáciles de controlar y se encaminaba hacia 
once de la revista uruguaya Los Huevos del Plata (marzo de 1968), la renovación poética del lenguaje parte de la plurisignificación que se le puede dar al signo dentro de un dispositivo determinado (aspecto que, como ya hemos dicho anteriormente, se equipara a la «significancia» descrita por Kristeva):

[... En los] Poemas matemáticos barrocos [...] El observador ya no se queda con la única posibilidad de mover las páginas o seguir un ritmo ya dado por la numeración de las mismas, sino que puede participar en un acto-creativo-condicionado (y decimos condicionado pues recibe los elementos con los cuales deberá jugar), al intercambiar, conjugar de distintas formas las hojas. Aceptando incluso de una fuente de luz que torna los elementos geométricos utilizados en una a-geometrización por las secuencias de sombras cortadas o difusas según la colocación de las hojas (Vigo, 1968: s/p.).

Ahora bien, independientemente de los procesos de participación activa que generan en el público-espectador, el eje central de los Poème Mathématique Baroque se basa en la conformación de nuevas expectativas lectoras; es decir, romper con lo que Josu Landa denomina como la «lectura ontológica del poema» (2002: 45-46), que no es otra cosa que la visión canónica que han impuesto las instituciones hegemónicas dentro del campo artístico y literario. En ese sentido, el poemario, al igual que el resto de los «poemas matemáticos», se transforma en una «intención significativa», en una "posibilidad estética». Esta acción propicia que el acto poético se constituya más allá del terreno de la escritura, puesto que al ser una «intención» o una «posibilidad» el poema de Vigo logra conjuntar en un mismo nivel de significancia tanto a la imagen como a la palabra escrita. En consecuencia, los procesos de análisis e interpretación convencionales quedan desarticulados, debido a que la obra poética ya no queda «reducida» a los conceptos aristotélicos de contenido y forma. Por ende, nos parece sumamente relevante el concepto de poesía propuesto por Landa.

una ordenación no-lineal, más pluridireccional de los signos en el espacio en blanco, algo así como un barroquismo visual» (De Campos, 1967: 5). Asimismo, debemos señalar que en esos precisos momentos (finales de los sesenta) la poesía concreta brasileña ya pasaba por su etapa final. Esto es importante, ya que fue una de las razones primordiales por las cuales Vigo tardó mucho tiempo en «reconocer» su labor poética. Sin embargo, el redescubrimiento del grupo le permitió al artista platense seguir explorando nuevos armados estéticos. De hecho, consciente de ello, Vigo les rindió un merecido homenaje tanto en el número veintidós de Diagonal Cero (junio de 1967) como en el libro De la poesía/proceso a la poesía para y/o a realizar (1969). 
Para Landa, «[...] el texto poético se presenta como un conjunto de signos articulados conforme a determinada intención» (2002: 44), puesto que «[...] ninguna presencia [dentro del discurso] es gratuita» (2002: 44). Dicha definición resulta ser muy significativa, si tenemos en cuenta los planteamientos estéticos desarrollados por Vigo en sus manifestaciones visuales. Esto se debe a que, siguiendo los postulados de Landa, el poema se configura a partir de una "vocación» o "pretensión poética» (Landa, 2002: 34); lo que propicia que el acto poético ya no sea visualizado como una estructura plenamente identificable (la concepción tradicional de poesía), sino más bien como un «[...] objeto hecho del lenguaje» (Paz, 1990: 9) ${ }^{17}$. Aspecto que, de alguna u otra manera, puede aplicarse a los «poemas matemáticos» del artista platense. Si bien existen marcadas diferencias entre los planteamientos estéticos de Vigo y las perspectivas críticas de Landa, no podemos ignorar que ambas visiones buscan establecer una nueva forma de ver y entender el acto poético. Por consiguiente, me parece adecuado visualizar a los «poemas matemáticos» desde los postulados críticos de Landa, ya que ambos poetas coinciden a la hora de señalar y enfatizar las ambigüedades conceptuales que rigen, hoy en día, el campo de la poesía:

Si un puñado de palabras en determinada disposición no constituye por sí solo el poema y halla (intencionalmente) su fuente de realización en una especie de «complemento de realidad» exterior al texto poético, ello indica que éste es virtualidad poética, que en términos ontológicos sólo es lo que puede o anuncia ser. Además, cabe recordar (vida supra, parágrafos 20, $21,22)$ que la materialidad de la obra poética es endeble, descansa en una dignidad sin mayor fundamento cósico y se reduce, por ende, a simple posibilidad [...] En consecuencia, hablar de la obra poética como mera posibilidad no equivale a hablar de vacuidad, de carencia total de realidad. El ser posibilidad ya implica un grado suficiente de determinabilidad $y$, por tanto, de cosidad, sin el cual serían impensables el acontecimiento poético y los procesos de que surgen. En realidad, dicha cosidad viene cimenta-

\footnotetext{
17 Es importante señalar que cuando Paz establece esta definición de poesía, el poeta mexicano pasaba por una etapa de reflexión poética. De hecho, es justamente en este periodo de tiempo (mediados de los sesenta y principios de los setenta) cuando Paz compone varios de sus poemarios más radicales: Blanco (1967), Topoemas (1968) y Discos visuales (1968). De igual forma, en esos años de reflexión, el poeta mexicano desarrolla una verdadera «obsesión» por la figura de Marcel Duchamp: en 1968, Paz publica un primer ensayo dedicado a la obra del pintor francés (Marcel Duchamp o El castillo de la pureza); y cinco años después, en 1973, escribe un segundo texto, en donde desarrolla algunas ideas que quedaron inconclusas (Apariencia desnuda. La obra de Marcel Duchamp).
} 
La «poesía matemática» de Edgardo Antonio Vigo: el poema como «intención»...

da por la misma condición lingüística del texto poético. Antes que nada, éste puede devenir poema porque los lenguajes lo permiten, lo posibilitan. Pero, además, la referida materialidad «inicial» actúa como condición de posibilidad de procesos que tienen lugar en un ámbito ontológico que no coincide con su materialidad sígnica (Landa, 2002: 80-81).

En conclusión, podemos afirmar que la «obra matemática» de Vigo no solo se contrapone a la concepción tradicional de lo que significa un poema, sino que además desajusta los procesos de análisis e interpretación que imponen las instituciones hegemónicas dentro del campo artístico y literario. Al definir a los «poemas matemáticos» como una «intención» o una "posibilidad», Vigo logra constituir una nueva forma de ver y entender el acto poético. Por tal motivo, lo que parece ser un simple «juego» de distribución visual termina por convertirse en una estrategia discursiva compleja que pone en duda los parámetros de lectura canónicos (leer y analizar el poema desde una visión ontológica y aristotélica). En ese sentido, se puede decir que cada uno de los «poemas matemáticos» de Vigo presenta al acto poético como una acción que va más allá de la «función simbólica del lenguaje».

Al establecer dentro de los lectores una suerte de "estupor estético» (no «leer» el texto en los términos que demanda la tradición), el artista platense configura, vía sus propuestas visuales, una forma poética que disuelve tanto los límites textuales como las convenciones literarias impuestas por las instituciones hegemónicas. Por ende, la «obra matemática» del artista platense, al no ser una concatenación de palabras sino más bien una serie de significantes activos, rompe con la esencia "sagrada»e «intangible» del poema. De tal manera que el proyecto estético de Vigo acaba por ser una propuesta artística que involucra íntimamente al lector con la finalidad de conformar un tipo de texto que desarrolle lo que Kristeva denomina como la «significancia». Con ello, el artista platense consigue constituir un proyecto estético que no solo dialoga y cuestiona a la tradición misma, sino que además visibiliza las múltiples contradicciones y deficiencias que aún subsisten en los procesos de análisis e interpretación de las obras literarias. 


\section{Referencias bibliográficas}

Aguilar, Gonzalo (2003), Poesía concreta brasileña: las vanguardias en la encrucijada modernista, Rosario, Beatriz Viterbo.

Asensi Pérez, Manuel (2003), Historia de la teoría de la literatura (el siglo XX hasta los años setenta), Valencia, Tirant lo Blanch.

Badiou, Alain (2009), Pequeño tratado de inestética, Buenos Aires, Prometeo Libros.

BAllart, Pere (2005), El contorno del poema, Barcelona, Acantilado.

BARISONE, Ornela (2014), «La escapada de la línea: Edgardo Antonio Vigo y la construcción de la poesía visual como género», en Revista Laboratorio, 11, s.p.

Blaine, Julien (1967), «Para empezar con la semiótica», en Diagonal Cero, 21, págs. 5-12.

Bugnone, Ana (2011), «Política, alegoría y disenso en la poética de Edgardo Antonio Vigo (1960-1976)», en De Arte, 10, págs. 253-264.

- (2017), Vigo. Arte, política y vanguardia, La Plata, Malisia.

DAvis, Fernando (2014), «Poéticas oblicuas. Grabado, cuerpos y poesía en Diagonal Cero», en Separata, 19, págs. 47-67.

FoucAult, Michel (1999), Entre filosofía y literatura. Obras esenciales, vol. 1, Barcelona, Paidós.

GradowczyK, Mario (2008), «Edgardo Antonio Vigo: Maquinaciones (19531962)», en Maquinaciones. Edgardo Antonio Vigo: trabajos 1953-1962, Buenos Aires, Centro Cultural de España en Buenos Aires, págs. 13-107.

Guerra Macías, Yolanda (2011), «¿Poesía visual o imagen poética?», en Samuel Gordon (Comp.), La poesía visual en México, Estado de México, UAEM, págs. 55-98.

Hernández Espinosa, Gabriel y Palma Castro, Alejandro (2017), «Dislocaciones de la poesía hispanoamericana: los lugares de enunciación y espacialidad del mensaje en la poesía visual de Guillermo Deisler y el Núcleo Post-Arte», en Mitologías hoy, 15, págs. 217-242. 
Higashi, Alejandro (2018), «El dificultismo de Eduardo Lizalde y Gerardo Deniz en la tradición de la poesía mexicana actual», en América Sin Nombre, 23, págs. 37-47.

KRISTEVA, Julia (1976), «Semanálisis y producción de sentido», en A. J Greimas et al., Ensayos de semiótica poética, Barcelona, Planeta, págs. 273-306.

- (1981), «El sujeto en cuestión: el lenguaje poético», en Claude Levi-Strauss (ed.), La identidad, Barcelona, Petrel, págs. 249-287.

- (1986), Al comienzo era el amor. Psicoanálisis y fe, Buenos Aires, Gedisa.

Landa, Josu (2002), Poética, México, FCE.

Palma Castro, Alejandro (2016), «De la extrañeza al dificultismo: los monstruos de Gerardo Deniz», en Michael McGrath (ed.), "This Spanish Thing": Essays in Honor of Edward F. Stanton, Newark, Juan de la Cuesta, págs. 221-236.

PAz, Octavio (1990), Los hijos del limo, Barcelona, Seix Barral.

VIGO, Edgardo Antonio (1966), «II Teorema Fundamental», en Diagonal Cero, 20, pág. 6.

- (1966), «Poema matemático», en Los Nuevos Imagineros Argentinos, exposición, La Plata, Facultad de Ciencias Médicas de la Universidad Nacional de La Plata.

- (1966), «Poema matemático», en Diagonal Cero, 20, s.p.

- (1966), «Poema matemático fallido», en Diagonal Cero, 20, pág. 7.

- (1967), Poème Mathématique Baroque, París, Contexte.

- (1968), «Nueva vanguardia poética en Argentina», en Los Huevos del Plata, 11, s. p.

- (1969), De la poesía/proceso a la poesía para y/o a realizar, La Plata, Diagonal Cero. 


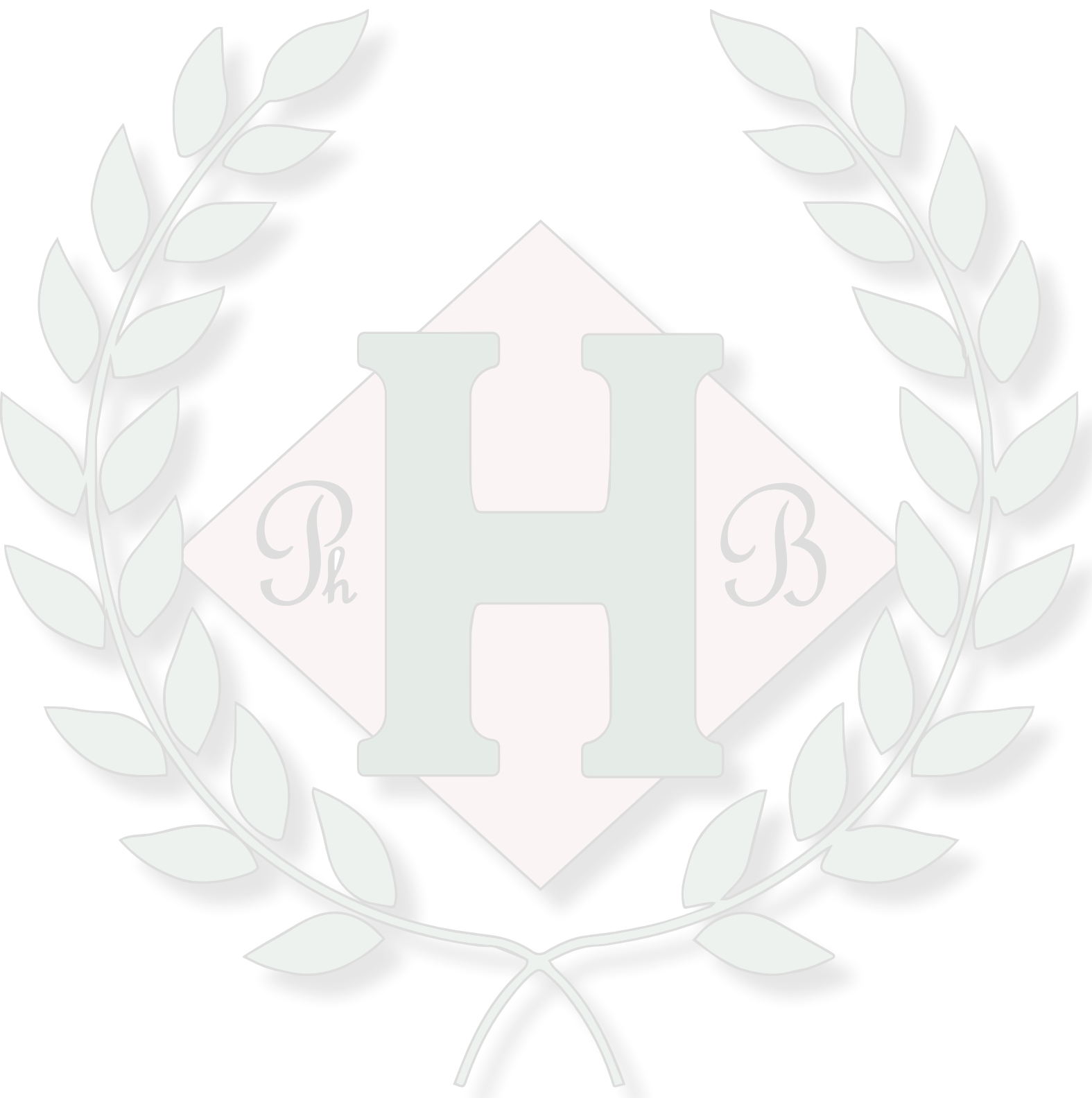

